\title{
Identification Comparative Analysis of mRNAs and IncRNAs in Regulating the Development of Goat Skeletal Muscle
}

\section{Xiuhui Zhao}

South China Agricultural University

Junning Ye

South China Agricultural University

Huiwen Xue

South China Agricultural University

Xian Zou

Guangdong Academy of Agricultural Sciences

Guangbin Liu

South China Agricultural University

Ming Deng

South China Agricultural University

Baoli Sun

South China Agricultural University

Yongqing Guo

South China Agricultural University

Dewu Liu

South China Agricultural University

Yaokun Li ( $\nabla$ ykli@scau.edu.cn )

South China Agricultural University

\section{Research Article}

Keywords: RNA, long noncoding, skeletal muscle, goats, myofiber, high-throughput nucleotide sequencing

Posted Date: February 3rd, 2022

DOI: https://doi.org/10.21203/rs.3.rs-1115813/v1

License: (c) (1) This work is licensed under a Creative Commons Attribution 4.0 International License.

Read Full License 


\section{Abstract}

Background: Meat yield and quality is one of the most important economic traits of livestock. Long noncoding RNAs (IncRNAs) is involved in the biological process of muscle differentiation and development. However, few studies have explored the regulatory role of IncRNA on muscle development after birth.

Results: The longissimus dorsi muscle of Leizhou black goat aged 0, 3 and 6 months was used to identify differential mRNA and differential IncRNA by high-throughput RNA sequencing. GO, KEGG and interaction network were used to analyzed the differential genes. We found that some target genes of DEmRNA and DE-IncRNA were mainly involved CN-NFAT signal pathway and the formation of branch fibers, which is related to normal muscle development. ENSCHIG00000006085 and ENSCHIG00000023270 are significantly concentrated in the biological process related to urea transporters, which has an important effect on maintaining the normal development of goats. ENSCHIG00000006085 and ENSCHIG00000023270 may be involved in the degradation of intracellular proteins and METTL11B may play a role in methylation modification of muscle proteins.

Conclusions: Our results show that some IncRNAs are involved in the regulation of protein during goat muscle development as well as provide a valuable resource for IncRNA studies and make a deeper understanding of the genetic basis and molecular mechanisms of the development of goat skeletal muscle.

\section{Background}

Skeletal muscle mass accounts for $40 \%-60 \%$ of the body weight of mammals, which has high economic value and is an important trait in goat breeding. The main functions of skeletal muscles are movement and protection, and they are also responsible for regulating the structure and metabolism of the body[1]. Skeletal muscle development in domestic animals can be divided into two stages: prenatal and postnatal, that is, the number of muscle fibers increased before birth and the volume of muscle fibers increased after birth. In the embryonic stage, the mesenchymal stem cells from the mesoderm first develop terminal differentiation into mononuclear myoblasts, then into spindle multinuclear myotubes, and finally further differentiation into myofibers[2]. In later development, the muscle fibers gradually differentiate into slow or fast muscle fibers to form a complete skeletal muscle[3].

LncRNA is a kind of ncRNA with a length of more than 200 bases, and has low or no protein coding potential. Compared with miRNA, IncRNA has poor evolutionary conservatism. Based on the genomic location relative to nearby protein-coding genes, IncRNA can be divided into sense IncRNA, anti-sense IncRNA, intron IncRNA, LincRNA and ERNA. These RNA usually regulate epigenetic silencing by chromatin remodeling. They also regulate splicing, recruit transcription factors, and regulate the stability of mRNA.

In recent years, more and more studies have confirmed that non-coding RNA are also important members of the muscle regulatory network. LncRNA widely exists in many kinds of organisms, and its function involves various aspects of cell life activities, ontogeny and disease occurrence. Current studies on 
IncRNA are mainly focused on screening and identifying IncRNA that exist in different tissues of different species or regulate life activities of the body.

Malat1 expression increased during the differentiation of myoblasts into myotubes, and the proliferation of myoblasts with targeted knockdown of Malat1 using siRNA was inhibited. It reveals that Malat1 is a novel downstream target of myostatin and has considerable ability to regulate myogenesis[4]. The expression of Linc-RAM was up-regulated during myogenesis, while the muscle regeneration of Linc-RAM knockout mice was impaired. Linc-RAM can directly bind MyoD to regulate the expression of myogenic genes, and then promote the assembly of MyoD -Baf60c-Brg1 complex, thus promoting the activation of myogenesis process[5]. SMD (Staufen1-mediated mRNA decay) occurs in mouse cells through partially complementary mRNA-IncRNA base pairing, and is triggered by mouse 1/2-sbsRNA to regulate myogenesis of $\mathrm{C} 2 \mathrm{C} 12$ cells[6]. Overexpression of Sirt1 antisense (AS) IncRNA promoted myoblast proliferation but inhibited differentiation. Sirt1 AS IncRNA interacts with Sirt1 3 'UTR, prolonging the halflife of Sirt1 mRNA, and promote Sirt1 translation and inhibit muscle formation by competing with miR34a[7].

In pairwise comparisons between the transcriptome sequencing of LD muscle tissue of 45-day old, 60day old and 105-day old goat fetuses and 3-day old lambs, 577 differentially expressed IncRNA were identified, which may have specific biological effects on goat early muscle development[8]. Although high-throughput sequencing technology has also been used to analyze the relationship between IncRNA and muscle differentiation, the information about IncRNA and muscle development is still limited, especially in goats.

\section{Results}

\section{Sequencing data quality control}

The raw reads from the 0-, 3- and 6-months old groups were analyzed for quality control before further analyses (Table 1). The Q30 value for each sample exceeded $91 \%$. The mapped ratio of clean reads with reference genome was over $82 \%$, and more than $80 \%$ sequences were uniquely mapped to the genome, indicating that the sequencing data was of high quality and suitable for subsequent analyses. 
Table 1

Quality statistics of different sample sequencing data

\begin{tabular}{|c|c|c|c|c|c|c|c|}
\hline $\begin{array}{l}\text { Sample } \\
\text { name }\end{array}$ & $\begin{array}{l}\text { Raw } \\
\text { reads }\end{array}$ & $\begin{array}{l}\text { Clean } \\
\text { reads }\end{array}$ & Q20(\%) & Q30(\%) & $\begin{array}{l}\text { Total } \\
\text { mapped }\end{array}$ & $\begin{array}{l}\text { Multiple } \\
\text { mapped }\end{array}$ & $\begin{array}{l}\text { Uniquely } \\
\text { mapped }\end{array}$ \\
\hline M0_1 & 91451366 & 90296570 & 97.04 & 92.13 & $\begin{array}{l}85035701 \\
(94.17 \%)\end{array}$ & $\begin{array}{l}11688824 \\
(12.94 \%)\end{array}$ & $\begin{array}{l}73346877 \\
(81.23 \%)\end{array}$ \\
\hline M0_2 & 99145950 & 97674536 & 97.31 & 92.65 & $\begin{array}{l}93669001 \\
(95.9 \%)\end{array}$ & $\begin{array}{l}9492508 \\
(9.72 \%)\end{array}$ & $\begin{array}{l}84176493 \\
(86.18 \%)\end{array}$ \\
\hline M0_3 & 97522592 & 96325710 & 97.01 & 91.95 & $\begin{array}{l}92859053 \\
(96.4 \%)\end{array}$ & $\begin{array}{l}6746407 \\
(7 \%)\end{array}$ & $\begin{array}{l}86112646 \\
(89.4 \%)\end{array}$ \\
\hline M3_1 & 93972708 & 92817732 & 96.76 & 91.46 & $\begin{array}{l}86174540 \\
(92.84 \%)\end{array}$ & $\begin{array}{l}10314379 \\
(11.11 \%)\end{array}$ & $\begin{array}{l}75860161 \\
(81.73 \%)\end{array}$ \\
\hline M3_2 & 115506982 & 114030402 & 97.53 & 93.41 & $\begin{array}{l}103869223 \\
(91.09 \%)\end{array}$ & $\begin{array}{l}12144916 \\
(10.65 \%)\end{array}$ & $\begin{array}{l}91724307 \\
(80.44 \%)\end{array}$ \\
\hline M3_3 & 109977218 & 108672712 & 97.44 & 93.14 & $\begin{array}{l}100660879 \\
(92.63 \%)\end{array}$ & $\begin{array}{l}9922360 \\
(9.13 \%)\end{array}$ & $\begin{array}{l}90738519 \\
(83.5 \%)\end{array}$ \\
\hline M6_1 & 91389622 & 90146316 & 97.55 & 93.43 & $\begin{array}{l}85143246 \\
(94.45 \%)\end{array}$ & $\begin{array}{l}7012263 \\
(7.78 \%)\end{array}$ & $\begin{array}{l}78130983 \\
(86.67 \%)\end{array}$ \\
\hline M6_2 & 109277192 & 107969018 & 97.40 & 93.08 & $\begin{array}{l}100742280 \\
(93.31 \%)\end{array}$ & $\begin{array}{l}12134444 \\
(11.24 \%)\end{array}$ & $\begin{array}{l}88607836 \\
(82.07 \%)\end{array}$ \\
\hline M6_3 & 115475130 & 114090040 & 97.54 & 93.39 & $\begin{array}{l}106918408 \\
(93.71 \%)\end{array}$ & $\begin{array}{l}13516743 \\
(11.85 \%)\end{array}$ & $\begin{array}{l}93401665 \\
(81.87 \%)\end{array}$ \\
\hline
\end{tabular}

The raw reads from the 0 -, 3- and 6-months old groups were analyzed for quality control before further analyses. The Q30 value for each sample exceeded $91 \%$. The mapped ratio of clean reads with reference genome was over $82 \%$, and more than $80 \%$ sequences were uniquely mapped to the genome, indicating that the sequencing data was of high quality and suitable for subsequent analyses.

\section{Differential Expression of mRNAs and IncRNAs}

To investigate the key mRNAs and IncRNAs involved in regulating goat skeletal muscle development, we used RNA-seq datasets from three time points to characterize their time-specific expression patterns (Table 2). When comparing the differentially expressed mRNAs (DE-mRNAs) across the three developmental stages, we found 192 (103 upregulated) DE-mRNAs between M0 and M3, 288 (167 upregulated) DE-mRNAs between M0 and M6, and 159(65 upregulated) DE-mRNAs between M6 and M3. When analyzing these DE-mRNAs, we found that 59,134 , and 58 mRNAs were uniquely expressed in one of the two samples in $M 0$ vs. M3, M0 vs. M6, and M6 vs. M3, respectively. We also analyzed the differentially expressed IncRNAs (DE-IncRNAs) between $\mathrm{M} 0$ and $\mathrm{M} 3, \mathrm{M} 0$ and $\mathrm{M} 6$, and $\mathrm{M} 6$ and $\mathrm{M} 3$, and detected 55(23 upregulated), 83(45 upregulated), and 33(10 upregulated) DE-IncRNAs. We found that 28, 
59 , and 18 IncRNAs were only expressed in the comparison of $\mathrm{M} 0$ and $\mathrm{M} 3, \mathrm{M} 0$ and $\mathrm{M} 6$, and $\mathrm{M} 6$ and $\mathrm{M} 3$, respectively.

Table 2

Number of DE-mRNAs and DE-IncRNAs at different time stage comparisons

\begin{tabular}{|lllllll|}
\hline \multirow{2}{*}{ DE-mRNAs } & & Upregulated & Downregulated & Uniquely Expressed & Total \\
& M0 vs. M3 & 103 & 89 & 59 & 192 \\
\cline { 2 - 6 } & M0 vs. M6 & 167 & 121 & 134 & 288 \\
\cline { 2 - 6 } & M6 vs. M3 & 65 & 94 & 58 & 159 \\
\hline \multirow{2}{*}{ DE-IncRNAs } & M0 vs. M3 & 23 & 32 & 28 & 55 \\
\cline { 2 - 6 } & M0 vs. M6 & 45 & 38 & 59 & 83 \\
\cline { 2 - 6 } & M6 vs. M3 & 10 & 23 & 18 & 33 \\
\hline
\end{tabular}

\section{GO analyses for DE-mRNAs and target genes of DE-IncRNAs}

In the M0 vs. M3 comparison, the top $20 \mathrm{GO}$ terms that were significantly related to mRNAs included respiratory chain, generation of precursor metabolites and energy, glucose metabolic process, oxidationreduction process, nucleotide salvage and intramolecular transferase activity, phosphotransferases (Table S1). In the M0 vs. M6 comparison, the most significantly enriched GO terms for the total mRNAs were associated with ribosome, structural constituent of ribosome, ribonucleoprotein complex, translation, structural molecule activity and non-membrane-bounded organelle (Table 3). In the M6 vs. M3 comparison, the top 30 processes for down and upregulated mRNAs were associated with nucleotide biosynthetic process, nucleoside phosphate biosynthetic process, death receptor binding, nerve growth factor receptor binding, pyrimidine nucleotide biosynthetic process and pyrimidine nucleotide metabolic process (Table S2).

In the M0 vs. M3 comparison, the top $30 \mathrm{GO}$ terms that were significantly related to DE-IncRNA target genes included urea transmembrane transporter activity, urea transport, one-carbon compound transport, urea transmembrane transport, amide transmembrane transporter activity and MLL1/2 complex (Table S3). In the M0 vs. M6 comparison, the most significantly enriched GO terms for the DE-IncRNA target genes were associated with GTP-Rho binding, Ras protein signal transduction, guanyl-nucleotide exchange factor activity, MLL1/2 complex, MLL1 complex and GTPase regulator activity (Table S4). In the M6 vs. M3 comparison, the top 30 processes for down and upregulated DE-IncRNA target genes were associated with urea transmembrane transporter activity, urea transport, one-carbon compound transport, urea transmembrane transport, amide transmembrane transporter activity and heterotrimeric G-protein complex (Table S5). 
Table 3

The top $20 \mathrm{GO}$ enrichment analyses of DE-mRNAs in M0 vs. M6

\begin{tabular}{|c|c|c|c|c|}
\hline $\begin{array}{l}\text { GO } \\
\text { Accession }\end{array}$ & Description & $\begin{array}{l}\text { Term } \\
\text { type }\end{array}$ & P Value & $\begin{array}{l}\text { gene } \\
\text { count }\end{array}$ \\
\hline GO:0005840 & ribosome & $\mathrm{CC}$ & $\begin{array}{l}4.65 \mathrm{E}- \\
27\end{array}$ & 59 \\
\hline GO:0003735 & structural constituent of ribosome & MF & $\begin{array}{l}1.08 \mathrm{E}- \\
26\end{array}$ & 58 \\
\hline G0:0030529 & ribonucleoprotein complex & $\mathrm{CC}$ & $\begin{array}{l}1.86 \mathrm{E}- \\
23\end{array}$ & 64 \\
\hline GO:0006412 & translation & $\mathrm{BP}$ & $\begin{array}{l}9.49 \mathrm{E}- \\
22\end{array}$ & 67 \\
\hline GO:0005198 & structural molecule activity & MF & $\begin{array}{l}4.10 \mathrm{E}- \\
20\end{array}$ & 73 \\
\hline GO:0043228 & non-membrane-bounded organelle & $\mathrm{CC}$ & $\begin{array}{l}1.54 \mathrm{E}- \\
15\end{array}$ & 106 \\
\hline G0:0043232 & $\begin{array}{l}\text { intracellular non-membrane-bounded } \\
\text { organelle }\end{array}$ & $\mathrm{CC}$ & $\begin{array}{l}1.54 \mathrm{E}- \\
15\end{array}$ & 106 \\
\hline GO:0044444 & cytoplasmic part & $\mathrm{CC}$ & $\begin{array}{l}5.13 \mathrm{E}- \\
10\end{array}$ & 114 \\
\hline GO:0044391 & ribosomal subunit & $\mathrm{CC}$ & $\begin{array}{l}5.25 \mathrm{E}- \\
10\end{array}$ & 16 \\
\hline GO:0044267 & cellular protein metabolic process & $\mathrm{BP}$ & $\begin{array}{l}2.51 \mathrm{E}- \\
08\end{array}$ & 147 \\
\hline GO:0005737 & cytoplasm & $\mathrm{CC}$ & $\begin{array}{l}4.47 \mathrm{E}- \\
08\end{array}$ & 138 \\
\hline GO:0044724 & $\begin{array}{l}\text { single-organism carbohydrate catabolic } \\
\text { process }\end{array}$ & $\mathrm{BP}$ & $\begin{array}{l}4.96 \mathrm{E}- \\
08\end{array}$ & 13 \\
\hline GO:0006096 & glycolysis & $\mathrm{BP}$ & $\begin{array}{l}6.23 \mathrm{E}- \\
08\end{array}$ & 11 \\
\hline GO:0016052 & carbohydrate catabolic process & $\mathrm{BP}$ & $\begin{array}{l}8.55 \mathrm{E}- \\
08\end{array}$ & 13 \\
\hline GO:0015935 & small ribosomal subunit & $\mathrm{CC}$ & $\begin{array}{l}1.40 \mathrm{E}- \\
07\end{array}$ & 9 \\
\hline GO:0019538 & protein metabolic process & $\mathrm{BP}$ & $\begin{array}{l}2.35 \mathrm{E}- \\
07\end{array}$ & 171 \\
\hline GO:0006091 & $\begin{array}{l}\text { generation of precursor metabolites and } \\
\text { energy }\end{array}$ & $\mathrm{BP}$ & $\begin{array}{l}3.55 \mathrm{E}- \\
07\end{array}$ & 27 \\
\hline
\end{tabular}




\begin{tabular}{|lllll|}
\hline $\begin{array}{l}\text { GO } \\
\text { Accession }\end{array}$ & Description & $\begin{array}{l}\text { Term } \\
\text { type }\end{array}$ & P Value & $\begin{array}{l}\text { gene } \\
\text { count }\end{array}$ \\
\hline G0:0006006 & glucose metabolic process & BP & $\begin{array}{l}6.83 \mathrm{E}- \\
07\end{array}$ & 13 \\
\hline G0:0006007 & glucose catabolic process & BP & $\begin{array}{l}9.27 \mathrm{E}- \\
07\end{array}$ & 11 \\
\hline G0:0019320 & hexose catabolic process & BP & $\begin{array}{l}1.17 \mathrm{E}- \\
06\end{array}$ & 11 \\
\hline
\end{tabular}

$\mathrm{CC}, \mathrm{MF}, \mathrm{BP}$ is the abbreviation of cellular component, molecular function and biological process, respectively.

\section{KEGG analyses for DE-mRNAs and target genes of DE- IncRNAs}

KEGG pathway analysis were applied to identify the pathways that were enriched in DE-mRNAs and DEIncRNAs target genes. The most significantly enriched pathways of DE-mRNAs are in the comparison of $\mathrm{MO}$ and M6, participating in Ribosome and Biosynthesis of amino acids (Table 4). The top 20 significantly enriched KEGG analyses for M0 vs. M3, and M6 vs.M3 are shown in Table S6 and Table S7. When comparing M0 vs. M3, M0 vs. M6, and M6 vs.M3, we found that in the most significantly enriched pathways, DE-IncRNAs target genes participated in 2-0xocarboxylic acid metabolism (Table S8) Ubiquitin mediated proteolysis, Focal adhesion (Table S9), and Retrograde endocannabinoid signaling (Table S10), respectively. 
Table 4

The top 20 significantly enriched Kyoto Encyclopedia of Genes and Genomes (KEGG) pathways of DE-mRNAs in M0 vs. M6

\begin{tabular}{|llll|}
\hline KEGG Pathway & Rich factor & P value & Gene number \\
\hline Ribosome & 0.211073 & $4.03 \mathrm{E}-12$ & 61 \\
\hline Biosynthesis of amino acids & 0.25 & 0.000259 & 19 \\
\hline Glycolysis / Gluconeogenesis & 0.241935 & 0.00275 & 15 \\
\hline Carbon metabolism & 0.146789 & 0.136471 & 16 \\
\hline Calcium signaling pathway & 0.124294 & 0.136471 & 22 \\
\hline Malaria & 0.188679 & 0.136471 & 10 \\
\hline Fructose and mannose metabolism & 0.225806 & 0.195687 & 7 \\
\hline ECM-receptor interaction & 0.146067 & 0.195687 & 13 \\
\hline 2-Oxocarboxylic acid metabolism & 0.294118 & 0.206114 & 5 \\
\hline Oxytocin signaling pathway & 0.116129 & 0.242966 & 18 \\
\hline Circadian entrainment & 0.132653 & 0.242966 & 13 \\
\hline African trypanosomiasis & 0.189189 & 0.242966 & 7 \\
\hline Insulin signaling pathway & 0.117241 & 0.242966 & 17 \\
\hline Focal adhesion & 0.105769 & 0.242966 & 22 \\
\hline Adrenergic signaling in cardiomyocytes & 0.114865 & 0.242966 & 17 \\
\hline Arginine and proline metabolism & 0.152542 & 0.242966 & 9 \\
\hline AMPK signaling pathway & 0.12 & 0.242966 & 15 \\
\hline Galactose metabolism & 0.1875 & 0.291047 & 6 \\
\hline Cell adhesion molecules (CAMs) & 0.109677 & 0.305387 & 17 \\
\hline Ovarian steroidogenesis & 0.138462 & 0.324482 & 9 \\
\hline
\end{tabular}

\section{Interaction Network of DE-mRNAs and DE-IncRNAs}

DE-mRNAs which co-located with IncRNA were further screened and Pearson correlation was performed on the co-located combinations. In the M0 vs. M3, IncRNA and mRNA appeared in pairs (Figure S1). In the M6 vs. M3, the DE-IncRNA-DE-mRNA interaction network was comprised of 12 IncRNAs and 8 proteincoding genes (Figure S2). In the M0 vs. M6, network images become more complex, among which 
TCONS_00078359 and other series of IncRNA expression were up-regulated, but METTL11B associated with them was down regulated (Fig. 1).

\section{Validation of RNA-Seq Data}

To validate the reliability of RNA-seq results, three DE-IncRNAs (TCONS_00169417, TCONS_00078365, TCONS_00182938) and three DE-mRNAs (RCAN1, MYOM3, RYR3,) were selected for qRT-PCR analysis (Fig. 2). The expression pattern of DE-IncRNAs and DE-mRNAs was found to be consistent with RNAsSeq, which confirmed the reliability of sequencing results.

\section{Discussion}

In this study, we systematically described the IncRNA and mRNA succession processes during the three stages in goat developmental LD. We found that IncRNA and mRNA expression were time-specific. Additionally, we performed real-time quantitative RT-PCR verification of the differential genes obtained by sequencing, which validated the time-specific IncRNA and mRNA expression patterns and the accuracy of the gene expression quantification.

RCAN (regulatory of calcineurin) is an endogenous CN (calcineurin) inhibitory protein, in which RCAN1 has been widely studied. RCAN1 plays an important role in many signal pathways: RCAN1 inhibits a series of downstream signal events by inhibiting CN-NFAT signal pathway; RCAN1 participates in the regulation of SOD1, stimulating the expression of SOD1 and improving SOD1 enzyme activity[9]; RCAN1 can also enhance the stability of IKBa protein, which forms a complex with NF-KB and inhibits NF-KB signaling pathway[10]. Through the analysis of DE-mRNA and DE-IncRNA, we found that the expression of RCAN1 was significantly different in the three stages, and was the highest at M0. Therefore, we speculate that the regulation of $\mathrm{CN}$ plays an important role in the muscle growth and development of goats at birth.

The OR gene superfamily was first found in Rattus norvegicus. It is a protein expressed by olfactory cells and belongs to the $G$ protein coupled receptor superfamily[11, 12]. OR is mainly expressed on the neuronal surface of olfactory epithelium, but some studies have found that it is also expressed on prostate, renal tubular epithelial cells and even primitive embryonic cells, indicating that the function of OR is not limited to olfaction[13-16]. In the isolated primary culture of human ASM (airway smooth muscle), OR51E2 is the most highly enriched OR transcript, and shows ligand selectivity and sensitivity to the short chain fatty acids (SCFAs) acetate and propionate, which are endogenous metabolic by-products of intestinal microbiota that slow down the proliferation of human ASM cells[17]. Myofiber branching of transgenic mice with specific over expression of mOR23 in muscle cells and dystrophic mice were analyzed. It was found that the overexpression of mOR23 in muscle resulted in the reduction of muscle fiber branches after muscle regeneration in non-malnourished mice and the severity of muscle fiber branches in mdx mice. The results were reported that mOR23 over-expression in muscle led to a decrease of myofiber branching after muscle regeneration in non-dystrophic mouse muscles and reduced the 
severity of myofiber branching in dystrophic mouse muscles[18]. In this study, we found that the expression of OR2AP1 was significantly different in the three stages, and increasing with the growth of goats. Therefore, we speculate that OR2AP1 may play an important role in controlling the formation of branch fibers in goat skeletal muscle.

The first urea transporter UT-A1 was isolated and identified from rabbit renal medulla, whose protein is encoded by SLC14A2 and SLC14A1 encodes UT-B protein, meanwhile, the rumen epithelium expressed a large amount of UT-B but no UT-A $[19,20]$. As a kind of ruminant, goat urea nitrogen cycle is very important to maintain nitrogen balance[21]. There are two main ways for urea to enter the rumen: with saliva and directly from the blood through the rumen wall epithelium. Due to the low permeability of cell membrane to urea, effective urea capture needs to be mediated by transporters. At present, it is considered that the transporters mediating urea transport in rumen epithelium mainly include UT-B channel protein and some aquaglyceroporins. Gastrointestinal microorganisms can express and secrete urea decomposing enzymes lacking in mammals, and can decompose urea into ammonia as a nitrogen source for their own growth and reproduction. At the same time, microbial products such as vitamins, short chain fatty acids (SCFA), peptides and microorganisms themselves (high-quality proteins) can be absorbed and utilized by host animals. In this process, urea nitrogen is preserved and reused, and converted into a variety of nutritional molecules for use by host animals[20, 22, 23]. According to GO analyses, ENSCHIG00000006085 and ENSCHIG00000023270 are significantly concentrated in the biological process related to urea transporters, which implies that the urea cycle has a deep impact on the growth and development of goat muscle.

Ubiquitin mediated proteolysis pathway is a protein degradation pathway of cytoplasmic ATP dependent non lysosomal pathway[24]. Ubiquitin is a heat stable protein, which is degraded by covalent amide bond with protein[25]. Ubiquitin related enzymes mainly include ubiquitin activating enzyme E1, ubiquitin carrier protein E2 and ubiquitin protein ligase E3. The substrate specificity of different E3 enzymes determines which proteins can be degraded. Ubiquitin mediated proteolysis can degrade tubulin and actin in Reticulocyte, as well as free protein in red blood cells a- Globin, abnormal denatured protein, and can degrade natural proteins such as cell transcription factors, intimal proteins and cyclins[25-27]. Ubiquitin controlled protein degradation has important physiological significance. It can not only remove wrong proteins, but also regulate cell growth cycle, DNA replication and chromosome structure. ENSCHIG00000025260, ENSCHIG0000010597, ENSCHIG00000024215, ENSCHIG00000023009, ENSCHIG00000015352, ENSCHIG0000020982 and ENSCHIG00000011824 Enriched in Ubiquitin mediated proteolysis pathway. Of them, ENSCHIG00000023009 is continuously lowered in M3 and M6 and the expression of ENSCHIG00000015352 was the highest at M3. Thus, we believe that ENSCHIG00000015352 and ENSCHIG00000023009 affect muscle development by regulating the degradation of intracellular proteins.

Protein methylation plays an important role in the growth and development of skeletal muscle. According to the different substrate proteins, protein methylation can be divided into histone methylation and nonhistone methylation[28, 29]. METTL21C is a non-histone lysine methyltransferase, belonging to the 
methyltransferase METTL 21 superfamily. It has protein lysine N-methyltransferase activity and is highly expressed in mouse skeletal muscle[30]. Knockdown of METTL21C gene in mouse skeletal muscle will reduce the trimethylation level of valine casein protein (VCP / p97), increase the accumulation of autophagic vacuoles and reduce skeletal muscle endurance[31]. METTL21C methylation modified HSPA8 protein, resulting in decreased expression of myocyte enhancer factor 2D (MEF2D) in mouse skeletal muscle[32]. In our study, with the development of goat LD, the expression of 17 IncRNAs such as TCONS_00078359 upgraded, while the expression of METTL11B co-located with TCONS_00078359 downgraded. Therefore, we speculate that METTL11B may play a role in the methylation of muscle protein, thus affecting the growth and development of muscle.

In conclusion, we found that some target genes of DE-mRNA and DE-IncRNA were mainly involved CNNFAT signal pathway and the formation of branch fibers, which is related to normal muscle development. ENSCHIG00000006085 and ENSCHIG00000023270 are significantly concentrated in the biological process related to urea transporters, which has an important effect on maintaining the normal development of goats. ENSCHIG00000006085 and ENSCHIG00000023270 may be involved in the degradation of intracellular proteins. METTL11B may play a role in methylation modification of muscle proteins. Our results are valuable resources for future studies on IncRNA biology, particularly those regarding goat muscle, and are helpful in understanding IncRNA function in goat.

\section{Materials And Methods}

\section{Animals and sample collection}

Nine Leizhou black goats were divided equally into three groups according to the age of 0,3 and 6 months old. All of them were raised under the same conditions with free access to food and water in natural lighting. All animals were slaughtered in accordance with animal welfare procedures, and after slaughter, we collected longissimus dorsi (LD) muscle samples of three growth stage (M0, M3 and M6). The tissue samples were immediately frozen in liquid nitrogen and stored at $-80^{\circ} \mathrm{C}$ before the analysis.

\section{RNA isolation, library preparation and sequencing}

The total RNA was isolated with the TRIzol reagent (Invitrogen, Carlsbad, CA, USA) and treated with DNase I (Qiagen, Beijing, China). Then 1\% agarose gel electrophoresis was used to assess the degradation and contamination of the RNA and RNA Nano6000 Assay Kit and the Bioanalyzer 2100 system (Agilent Technologies, Santa Clara, CA, USA) were used to check the integrity of RNA.

The total RNA ( $3 \mu \mathrm{g})$ was used as input material for each sample preparation. First, Epicentre Ribozero $^{\mathrm{TM}} \mathrm{M}_{\mathrm{rRNA}}$ Removal Kit (Epicentre, Madison, WI, USA) was applied to remove the ribosomal RNA (rRNA) and ethanol precipitation was used to clean up the rRNA-free residue. Subsequently, sequencing libraries were generated using the rRNA-depleted RNA with the NEBNext ${ }^{\circledR}$ Ultra ${ }^{\mathrm{TM}}$ Directional RNA Library Prep Kit 
for Illumina ${ }^{\circledR}$ (NEB, Beverly, MA, USA), according to the manufacturer's instructions. Briefly, fragmentation was carried out in NEBNext First Strand Synthesis Reaction Buffer (5x). First strand cDNA was synthesized using random hexamer primers and M-MuLV reverse transcriptase (RNaseH). The second strand cDNA synthesis was then performed using DNA polymerase I and RNaseH. In the reaction buffer, dNTPs with dTTP were replaced by dUTP. The remaining overhangs were converted into blunt ends via exonuclease/polymerase activities. After the adenylation of the 30 -ends of the DNA fragments, NEBNext Adaptors containing a hairpin loop structure were ligated to prepare for the hybridization. To preferentially select cDNA fragments of $150-200$ bp in length, the library fragments were purified using the AMPure XP system (Beckman Coulter, Miami, FL, USA). Subsequently, $3 \mu \mathrm{L}$ USER enzyme (NEB, Beverly, MA, USA) was incubated with size-selected, adaptor-ligated cDNA at $37^{\circ} \mathrm{C}$ for $15 \mathrm{~min}$, followed by 5 min at $95^{\circ} \mathrm{C}$. A PCR amplification was then performed with Phusion High-Fidelity DNA polymerase, Universal PCR primers and Index $(X)$ Primer. Finally, the products were purified using the AMPure XP system (Beckman Coulter, Miami, FL, USA), and the library quality was assessed using the Agilent Bioanalyzer 2100 system (Agilent Technologies, Santa Clara, CA, USA).

\section{Data analysis}

The constructed libraries were sequenced on an Illumina HiSeq 4000 platform, and 150-bp paired-end reads were generated. After removing the sequence containing adapter and the reads containing ploy- $\mathrm{N}$ and low-quality reads through in-house Perl scripts, clean data were obtained. All the downstream analyses were based on the clean data with high quality. To obtain the high-quality reads, we performed the following filtering process: we removed the reads containing more than $10 \%$ unknown nucleotides and the reads containing more than $50 \%$ low quality nucleotides with Phred with a quality under 20 . Mapping to the reference genome was the next step. Reads that passed the quality control were then mapped to the Ovis aries reference genome (Oar_v3.1). The index of the reference genome was built using bowtie2 v2.2.8, and paired-end clean reads were aligned to the reference genome using HISAT2 (v2.0.4). HISAT2 was run with "-rna-strandness RF", and other parameters were set as default. Next was the transcriptome assembly. The mapped reads of each sample were assembled by StringTie (v1.3.1).

Before the screening, Cu merge was used to create the set of transcripts. Then, the IncRNA screening was carried out through the following steps: Step1: select the number of transcripts with 2 exons; Step2: out of the results from step1, select the transcripts with a length >200 bp; Step3: annotate the above transcripts using the Cu compare software; Step4: calculate the expression level of each transcript by $\mathrm{Cu}$ quant, and select the transcripts with FPKM 0.1; Step5: coding the potential screening: the coding potential of the transcript was predicted by three softwares: CNCl (Coding-Non-Coding-Index) (v2), CPC (Coding Potential Calculator) (0.9-r2), and PFAM (Pfam Scan) (v1.3); the intersection of the transcripts without a coding potential screened through the above three softwares with the default parameter was predicted as the IncRNA dataset. 
The Ballgown was utilized to perform the straightforward linear-model-based differential expression analyses within a default statistical modeling framework. The transcripts with p-adjust $<0.05$ were assigned as being differentially expressed.For each IncRNA locus, the 100-kb upstream and downstream regions were chosen to screen the co-located genes through the UCSC Genome Browser.

\section{GO and KEGG enrichment analysis}

In this study, the mRNAs within a 100-kb window upstream or downstream of DE-s were served as a cistarget mRNAs dataset of DE-IncRNAs.

Gene Ontology (GO) enrichment analysis was used on the target gene candidates of differentially expressed mRNAs and IncRNAs. GO-seq based Wallenius non-central hyper-geometric distribution[33], which could adjust for gene length bias, was implemented for $\mathrm{GO}$ enrichment analysis.

KEGG[34] is a database resource for understanding high-level functions and utilities of the biological system, such as the cell, the organism and the ecosystem, from molecular-level information, especially large-scale molecular datasets generated by genome sequencing and other high-throughput experimental technologies (http://www.genome.jp/kegg/). We used KOBAS[35] software to test the statistical enrichment of the target gene candidates in KEGG pathways.

\section{Construction of DEmRNAs-DElncRNAs Interaction Network}

The combinations with pearson correlation lower than 0.60 and negative correlation were excluded. The relationship between DE-IncRNAs and DE-mRNAs was visualized using Cytoscape (V3.5.1).

\section{qRT-PCR Verification}

The cDNA for qRT-PCR was synthesized using PrimeScript RT Reagent Kit With gDNA Eraser (TaKaRa, Dalian, China) and qRT-PCR was performed using 2xUltra SYBR Green qPCR Mix (Cistro, Shanghai, China). Capra hircus $\beta$-actin served as the endogenous control for mRNA and IncRNA expression analyses.

\section{Declarations}

\section{Acknowledgements}

Not applicable.

\section{Authors' contributions}


X.Z. and Y.L collected samples, X.Z. curated data, Y.G. and Y.L provided methodology, G.L. and D.L administrated project, G.L. and B.S provided software, Y.G., M.D. and Y.L. supervised project, H.X. and X.Z validated data, X.Z. and J.Y. wrote original draft, and Y.L. reviewed and edited article. All authors have read and approved the manuscript.

\section{Funding}

This research was supported by the Modern Agricultural Industrial Technology System of Guangdong Province (2021KJ127).

\section{Availability of data and materials}

The datasets generated and/or analysed during the current study are available in the data base SRA (Sequence Read Archive) in NCBI repository, and the BioProject ID is PRJNA795300.

\section{Ethics approval and consent to participate}

All experimental procedures and sample collection methods complied with the Regulation on the Administration of Laboratory Animals (CLI.2.293192, 2017 Revision, State Council, China) and were performed in strict accordance with the Institutional Animal Care and Use Committees of South China Agricultural University (approval no. 2018-P002). Our study is reported in accordance with ARRIVE guidelines (https://arriveguidelines.org).

\section{Consent for publication}

Not applicable.

\section{Competing interests}

The authors declare that they have no Competing interests.

\section{References}

1. Braun $T$, Gautel M: Transcriptional mechanisms regulating skeletal muscle differentiation, growth and homeostasis. Nat Rev Mol Cell Biol 2011, 12(6):349-361.

2. Buckingham M, Vincent SD: Distinct and dynamic myogenic populations in the vertebrate embryo. Curr Opin Genet Dev 2009, 19(5):444-453. 
3. Quiat D, Voelker KA, Pei J, Grishin NV, Grange RW, Bassel-Duby R, Olson EN: Concerted regulation of myofiber-specific gene expression and muscle performance by the transcriptional repressor Sox6. Proc Natl Acad Sci U S A 2011, 108(25):10196-10201.

4. Watts R, Johnsen VL, Shearer J, Hittel DS: Myostatin-induced inhibition of the long noncoding RNA Malat1 is associated with decreased myogenesis. Am J Physiol Cell Physiol 2013, 304(10):C9951001.

5. Yu XH, Zhang Y, Li TT, Ma Z, Jia HX, Chen Q, Zhao YX, Zhai LL, Zhong R, Li CY et al: Long non-coding RNA Linc-RAM enhances myogenic differentiation by interacting with MyoD. Nat Commun 2017, 8.

6. Wang JS, Gong CG, Maquat LE: Control of myogenesis by rodent SINE-containing IncRNAs. Genes \& Development 2013, 27(7):793-804.

7. Wang GQ, Wang Y, Xiong Y, Chen XC, Ma ML, Cai R, Gao Y, Sun YM, Yang GS, Pang WJ: Sirt1 AS IncRNA interacts with its mRNA to inhibit muscle formation by attenuating function of miR-34a. Sci Rep 2016, 6:21865.

8. Zhan S, Dong Y, Zhao W, Guo J, Zhong T, Wang L, Li L, Zhang H: Genome-wide identification and characterization of long non-coding RNAs in developmental skeletal muscle of fetal goat. $B M C$ Genomics 2016, 17:666.

9. Ermak G, Cheadle C, Becker KG, Harris CD, Davies KJ: DSCR1(Adapt78) modulates expression of SOD1. FASEB J 2004, 18(1):62-69.

10. Kim YS, Cho KO, Lee HJ, Kim SY, Sato Y, Cho YJ: Down syndrome candidate region 1 increases the stability of the IkappaBalpha protein: implications for its anti-inflammatory effects. $J$ Biol Chem 2006, 281(51):39051-39061.

11. Gaillard I, Rouquier S, Chavanieu A, Mollard P, Giorgi D: Amino-acid changes acquired during evolution by olfactory receptor $912-93$ modify the specificity of odorant recognition. Hum Mol Genet 2004, 13(7):771-780.

12. Buck $L$, Axel R: A novel multigene family may encode odorant receptors: a molecular basis for odor recognition. Cell 1991, 65(1):175-187.

13. Young JM, Trask BJ: The sense of smell: genomics of vertebrate odorant receptors. Hum Mol Genet 2002, 11(10):1153-1160.

14. Yuan TT, Toy P, McClary JA, Lin RJ, Miyamoto NG, Kretschmer PJ: Cloning and genetic characterization of an evolutionarily conserved human olfactory receptor that is differentially expressed across species. Gene 2001, 278(1-2):41-51.

15. Kalbe B, Schlimm M, Wojcik S, Philippou S, Massberg D, Jansen F, Scholz P, Luebbert H, Ubrig B, Osterloh $S$ et al: Olfactory signaling components and olfactory receptors are expressed in tubule cells of the human kidney. Arch Biochem Biophys 2016, 610:8-15.

16. Goto T, Salpekar A, Monk M: Expression of a testis-specific member of the olfactory receptor gene family in human primordial germ cells. Mol Hum Reprod 2001, 7(6):553-558.

17. Aisenberg WH, Huang J, Zhu W, Rajkumar P, Cruz R, Santhanam L, Natarajan N, Yong HM, De Santiago B, Oh JJ et al: Defining an olfactory receptor function in airway smooth muscle cells. Sci 
Rep 2016, 6:38231.

18. Pichavant C, Burkholder TJ, Pavlath GK: Decrease of myofiber branching via muscle-specific expression of the olfactory receptor mOR23 in dystrophic muscle leads to protection against mechanical stress. Skelet Muscle 2016, 6:2.

19. You G, Smith CP, Kanai Y, Lee WS, Stelzner M, Hediger MA: Cloning and characterization of the vasopressin-regulated urea transporter. Nature 1993, 365(6449):844-847.

20. Stewart GS, Graham C, Cattell S, Smith TP, Simmons NL, Smith CP: UT-B is expressed in bovine rumen: potential role in ruminal urea transport. Am J Physiol Regul Integr Comp Physiol 2005, 289(2):R605-r612.

21. Reynolds CK, Kristensen NB: Nitrogen recycling through the gut and the nitrogen economy of ruminants: an asynchronous symbiosis. J Anim Sci 2008, 86(14 Suppl):E293-305.

22. Reese AT, Pereira FC, Schintlmeister A, Berry D, Wagner M, Hale LP, Wu A, Jiang S, Durand HK, Zhou $X$ et al: Microbial nitrogen limitation in the mammalian large intestine. Nat Microbio/2018, 3(12):1441-1450.

23. Holmes AJ, Chew YV, Colakoglu F, Cliff JB, Klaassens E, Read MN, Solon-Biet SM, McMahon AC, Cogger VC, Ruohonen K et al: Diet-Microbiome Interactions in Health Are Controlled by Intestinal Nitrogen Source Constraints. Cell Metab 2017, 25(1):140-151.

24. Hershko A: Some lessons from my work on the biochemistry of the ubiquitin system. J Biol Chem 2009, 284(16):10291-10295.

25. Khandros E, Thom CS, D'Souza J, Weiss MJ: Integrated protein quality-control pathways regulate free a-globin in murine $\beta$-thalassemia. Blood 2012, 119(22):5265-5275.

26. Mischo HE, Chun Y, Harlen KM, Smalec BM, Dhir S, Churchman LS, Buratowski S: Cell-Cycle Modulation of Transcription Termination Factor Sen1. Mol Cel/2018, 70(2):312-326.e317.

27. Deng T, Yan G, Song X, Xie L, Zhou Y, Li J, Hu X, Li Z, Hu J, Zhang Y et al: Deubiquitylation and stabilization of p21 by USP11 is critical for cell-cycle progression and DNA damage responses. Proc Natl Acad Sci U S A 2018, 115(18):4678-4683.

28. Greer EL, Shi Y: Histone methylation: a dynamic mark in health, disease and inheritance. Nat Rev Genet 2012, 13(5):343-357.

29. Xu Y, Ding J, Huang Q, Deng NY: Prediction of protein methylation sites using conditional random field. Protein Pept Lett 2013, 20(1):71-77.

30. Kernstock S, Davydova E, Jakobsson M, Moen A, Pettersen S, Mælandsmo GM, Egge-Jacobsen W, Falnes P: Lysine methylation of VCP by a member of a novel human protein methyltransferase family. Nat Commun 2012, 3:1038.

31. Wiederstein JL, Nolte H, Günther S, Piller T, Baraldo M, Kostin S, Bloch W, Schindler N, Sandri M, Blaauw B et al: Skeletal Muscle-Specific Methyltransferase METTL21C Trimethylates p97 and Regulates Autophagy-Associated Protein Breakdown. Cell Rep 2018, 23(5):1342-1356. 
32. Zoabi M, Zhang L, Li TM, Elias JE, Carlson SM, Gozani O: Methyltransferase-like 21C (METTL21C) methylates alanine tRNA synthetase at Lys-943 in muscle tissue. J Biol Chem 2020, 295(33):1182211832.

33. Young MD, Wakeeld MJ, Smyth GK, Oshlack A: goseq: Gene Ontology testing for RNA-seq datasets. 2012.

34. Kanehisa M, Araki M, Goto S, Hattori M, Hirakawa M, Itoh M, Katayama T, Kawashima S, Okuda S, Tokimatsu T et al: KEGG for linking genomes to life and the environment. Nucleic Acids Res 2008, 36(Database issue):D480-484.

35. Mao X, Cai T, Olyarchuk JG, Wei L: Automated genome annotation and pathway identification using the KEGG Orthology (KO) as a controlled vocabulary. Bioinformatics 2005, 21(19):3787-3793.

\section{Figures}




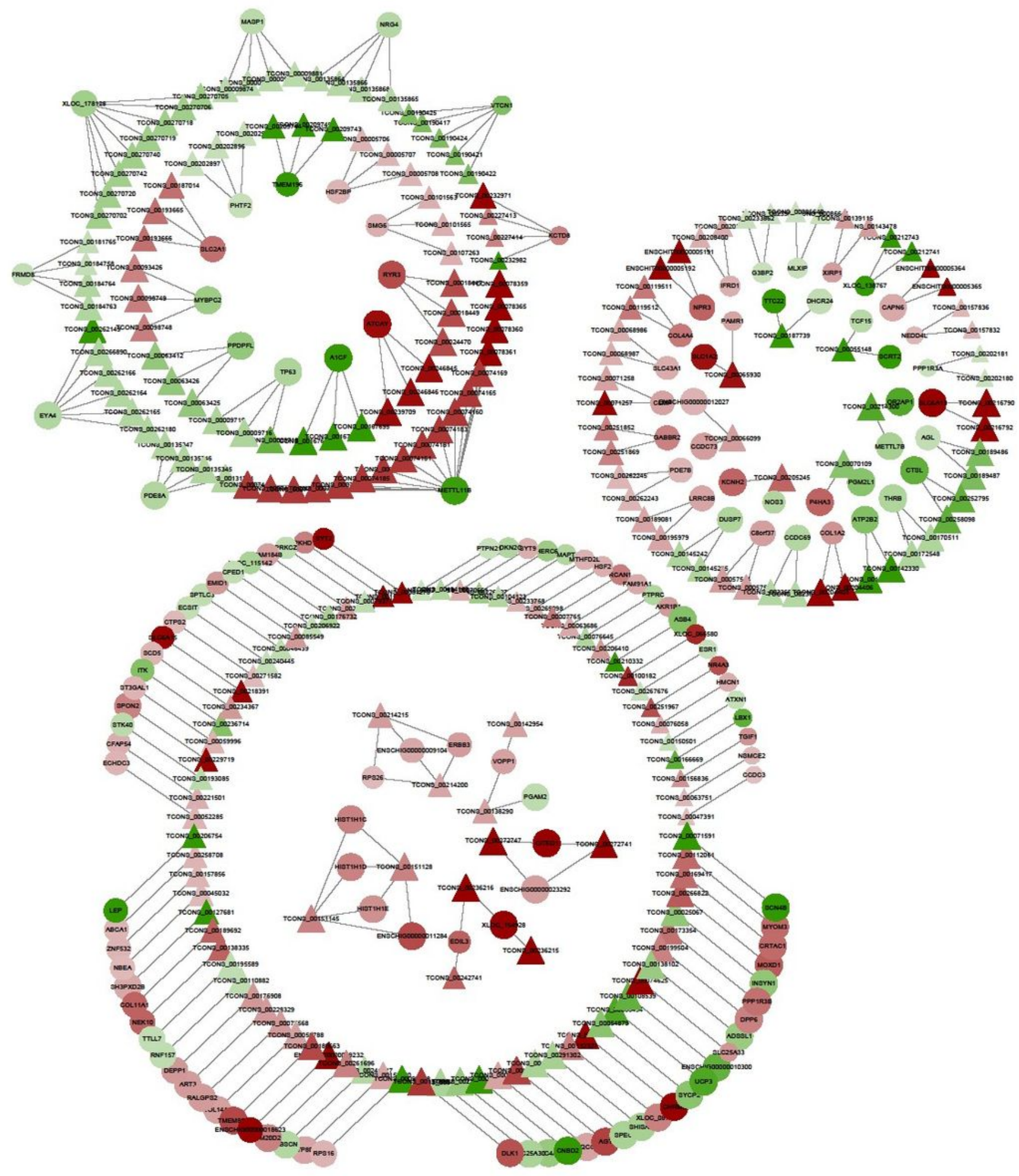

\section{Figure 1}

The mRNA-IncRNA network for the comparisons of M0 vs. M6. The triangle represents IncRNA and the circle represents mRNA. Red means upregulated and green means downregulated and the larger the $\log _{2}$ FoldChange value, the stronger the color. The sizes of labels were arranged according to the $P$ value, the smaller $P$ value, the larger the size. 
$\rightarrow$ Q-PCR $\quad \rightarrow$ RNA-seq

TCONS_00169417
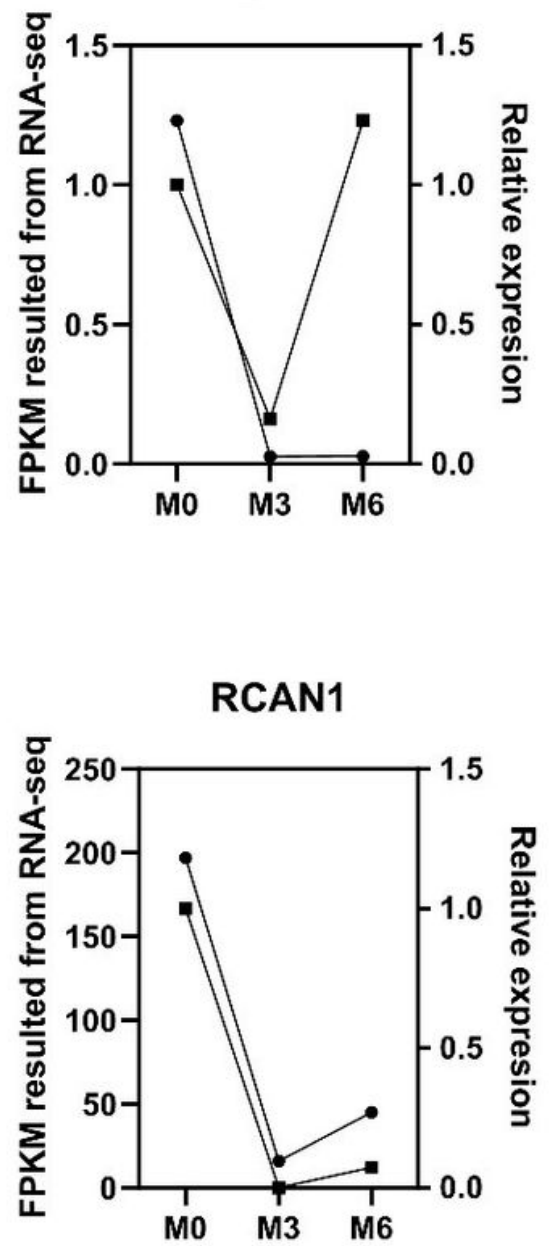

TCONS_00078365

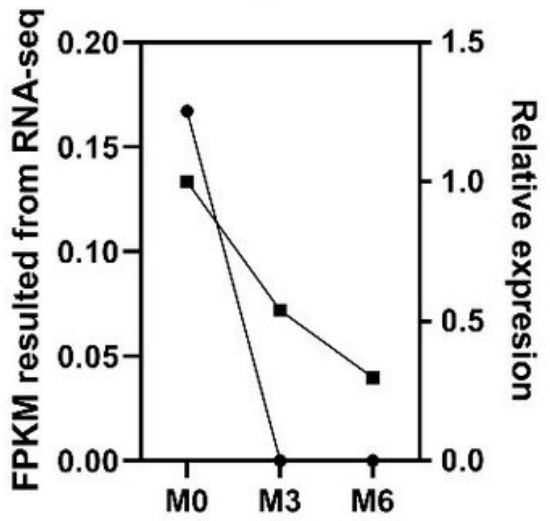

MYOM3

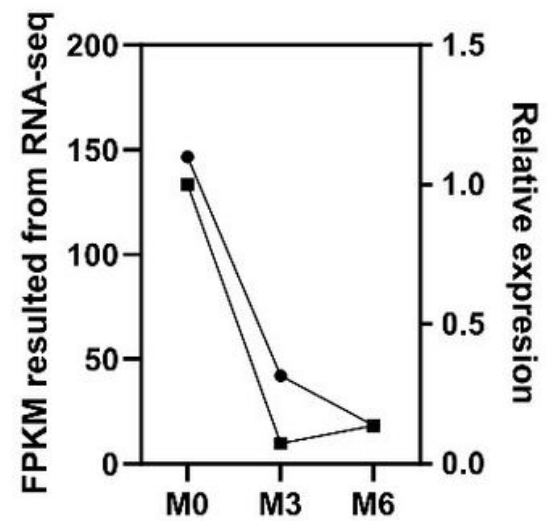

TCONS_00182938

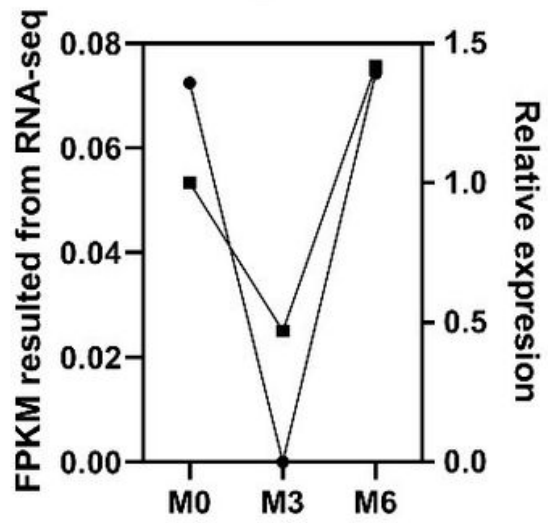

RYR3

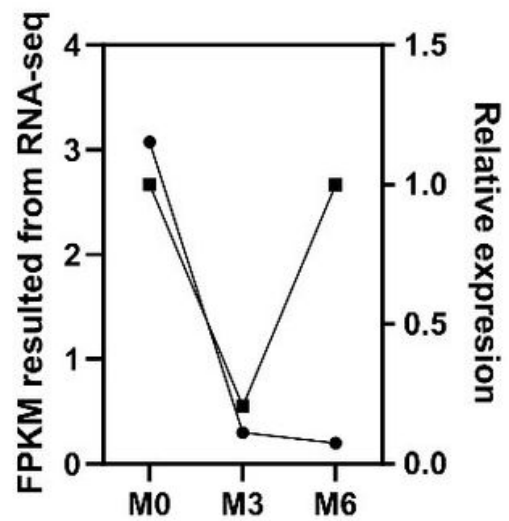

Figure 2

RT-qPCR results of mRNAs and IncRNAs in M0, M3 and M6 groups.

\section{Supplementary Files}

This is a list of supplementary files associated with this preprint. Click to download.

- FigureS1.pdf

- Figures2.pdf

- TableS1.xIsx

- Tables10.xIsx

- Tables2.xIsx 
- Tables3.xIsx

- Tables4.xIsx

- Tables5.xlsx

- Tables6.xlsx

- TableS7.xlsx

- Tables8.xlsx

- Tables9.xIsx 